\title{
A Simplistic Overview of Machine Learning
}

\author{
Rajesh Yadav \\ Department of Computer Science, V.K.Krishna Menon College, Mumbai, Maharashtra, India
}

\begin{abstract}
Article Info

Volume 8, Issue 5

Page Number : 184-187

Publication Issue :

September-October-2021

While dealing with machine learning, a computer learns first to perform a roles/task by learning a set of training examples. The computer performs then the same task along with data it hasn't found before. This paper presents a brief overview of machine-learning types along with instances. The paper also covers differences between supervised and unsupervised learning.

Article History

Accepted : 06 Sep 2021

Keywords : Machine Learning, Supervised, Unsupervised, reinforcement, decision tree.

Published: 20 Sep 2021
\end{abstract}

\section{INTRODUCTION}

The Machine Learning field is developed from the expanded field of Artificial Intelligence, which aims to imitate human intelligent abilities by machines. A dictionary definition of machine learning includes phrases such as "to gain knowledge, or understanding of, or skill in, by study, instruction, or experience," and "modification of a behavioral tendency by experience".

Machine learning usually refers to the variations in devices that perform roles associated with artificial intelligence (AI). Such roles involves recognition, planning, robot control, prediction, etc. The "changes" might be either development to preperforming systems synthesis of new systems.

\section{IMPORTANCE OF MACHINE LEARNING}

- A few undertakings can't be characterized well besides as a visual cue; that is, we could possibly indicate input/yield combines yet not a brief connection among inputs and wanted yields. We might want machines to have the options to change their interior design to deliver right yields for countless example information sources and consequently appropriately oblige their feedback/yield capacity to estimate the relationship understood in the models.

- It is conceivable that tucked away among enormous heaps of information are significant connections and relationships.

- ML techniques can frequently be utilized to extricate these connections (data mining).

- Human planners regularly produce machines that don't fill in just as wanted in the conditions

Copyright: (C) the author(s), publisher and licensee Technoscience Academy. This is an open-access article distributed under the terms of the Creative Commons Attribution Non-Commercial License, which permits unrestricted non-commercial use, distribution, and reproduction in any medium, provided the original work is properly cited 
in which they are utilized. Indeed, certain qualities of the workplace probably won't be totally known at configuration time.

- $\quad$ ML techniques can be utilized for hands-on progress of existing machine plans.

- The measure of information accessible about specific undertakings may be excessively enormous for unequivocal encoding by people. Machines that get familiar with this information progressively could possibly catch a greater amount of it than people would need to record.

- Environments change after some time. Machines that can adjust to a changing climate would decrease the requirement for consistent update.

- New information about undertakings is continually being found by people.

There is a steady stream of new occasions on the planet. Continuous up gradation of ML frameworks to adjust to new information is unfeasible, yet $\mathrm{ML}$ techniques could possibly follow a lot of it.

\section{TYPES OF MACHINE LEARNING}

ML is not only about classification.

The following are the classes of problems that exist:

a) Classification-learning: explore to put examples into predefined classes

b) Association-learning: explore relation-ships between the attributes.

c) Clustering: clusters data of similar pattern in one.

d) Numerical prediction: explore a numericquantity instead of a class.

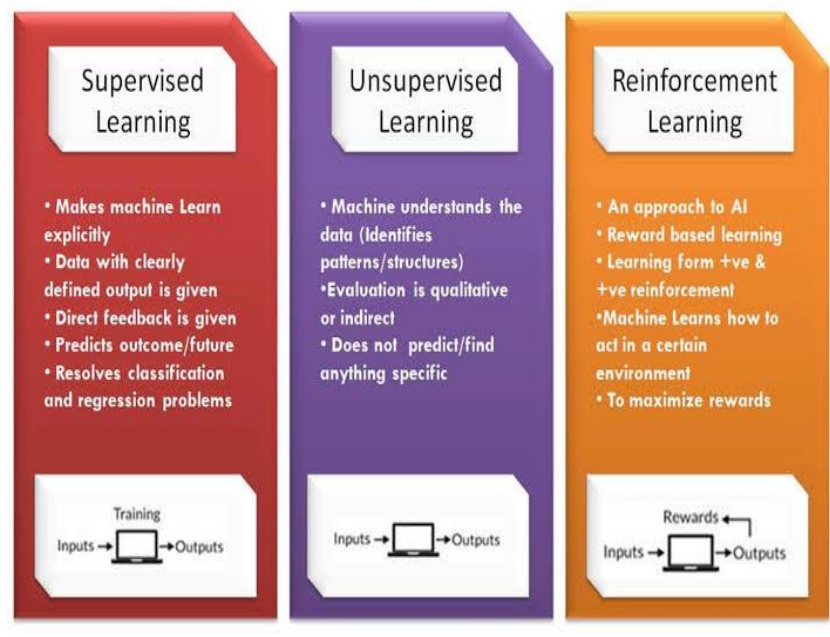

Fig 1.Types of ML

\section{1) Supervised Learning}

Supervised learning occurs within the sight of an administrator actually like learning performed by a little youngster with the assistance of his instructor. As a kid is prepared to perceive organic products, colors, numbers under the oversight of an educator this technique is managed learning. In this strategy, each progression of the youngster is checked by the instructor and the kid gains from the yield that he needs to deliver.

\section{A) Working nature of supervised learning:}

In the directed ML calculation, the yield/results/feedback is now known. There is a planning of contribution with the yield/feedback. Thus, to make a model, the machine is taken care of with heaps of preparing input information (having input and relating yield known). The preparation information helps in accomplishing a degree of precision for the made information model. The assembled model is currently fit to be taken care of with new info information and foresee the results. Directed learning is a quick learning instrument with high precision. The managed learning issues incorporate relapse and grouping issues.

A portion of the supervised learning calculations are:

- Decision Trees,

- K-Nearest Neighbor, 
- Simple Regression,

- Support Vector Machine and Neural Networks.

\section{2) Unsupervised Learning}

Unsupervised learning occurs without the assistance of a director very much like a fish figures out how to swim without help from anyone else. It is a free learning measure.

In this model, as there is no yield planned with the info, the objective qualities are obscure / unlabeled. The framework needs to take in without anyone else from the information contribution to it and recognize the secret examples.

\section{A) Working nature of unsupervised learning}

As there are no known yield esteems that can be utilized to construct an intelligent model between the information and yield, a few strategies are utilized to mine information rules, examples and gatherings of information with comparable kinds. These gatherings help the end-clients to comprehend the information better just as track down a significant yield.

The fed inputs are not as an appropriate construction very much like preparing information is (in directed learning). It might contain exceptions, boisterous information; and so on. These information sources are together taken care of to the framework. While preparing the model, the information sources are coordinated to shape groups.

The unsupervised learning calculations incorporate Clustering and Association Algorithms, for example, Apriori, K-implies grouping and other affiliation rule mining calculations.

At the point when new information is taken care of to the model, it will anticipate the result as a class mark to which the info has a place. Assuming the class name is absent, another class will be created.

While going through the method involved with finding designs in the information, the model changes its boundaries without help from anyone else consequently it is additionally called self-arranging.
The bunches will be shaped by discovering the likenesses among the information sources.

For Example, while purchasing items on the web, on the off chance that margarine is placed in the truck, it proposes purchasing bread, cheddar, and so on.

The unaided model glances at the information focuses and predicts different properties that are related with the item.

\section{3) Reinforcement Learning}

In this sort of learning, the calculation learns by criticism system and past encounters. It is constantly wanted that each progression in the calculation is taken to arrive at an objective.

So at whatever point the subsequent stage is to be taken, it gets the input from the past advance, alongside the gaining from the experience to foresee what could be the following best advance. This cycle is additionally called an experimentation interaction to arrive at the objective.

Support learning is a drawn out iterative interaction. The more the quantity of criticisms, the more precise the framework becomes. Fundamental support learning is additionally called Markov Decision Process.

Support Learning is utilized in preparing robots, selfpropelled vehicles, programmed the board of stock, and so forth.

Some well known instances of Reinforcement Learning include: Q-Learning, Profound Adversarial Networks.

\section{DIFFERENCE BETWEEN SUPERVISED \& UNSUPERVISED LEARNING}

The following describes the differentiation of supervised and unsupervised learning. 


\begin{tabular}{|c|c|}
\hline Supervised & Unsupervised \\
\hline Input Data is labelled & Input Data is Unlabelled \\
\hline Uses training Dataset & Uses just input dataset \\
\hline $\begin{array}{l}\text { Data is classified based on } \\
\text { training dataset }\end{array}$ & $\begin{array}{l}\text { Uses properties of given } \\
\text { data to classify it. }\end{array}$ \\
\hline Used for prediction & Used for Analysis \\
\hline $\begin{array}{l}\text { Divided into two types } \\
\text { Regression \& Classification }\end{array}$ & $\begin{array}{l}\text { Divided into two types } \\
\text { Clustering \& Association }\end{array}$ \\
\hline Known number of classes & $\begin{array}{l}\text { Unknown number of } \\
\text { classes }\end{array}$ \\
\hline$\left.x_{2}\right|_{0} \underbrace{\stackrel{x}{x} \times}_{0}$ & $x_{2}\left(\begin{array}{ll}80 \\
00\end{array}\right.$ \\
\hline$x_{1}$ & $x_{2}$ \\
\hline $\begin{array}{l}\text { Use off-line analysis of } \\
\text { data }\end{array}$ & $\begin{array}{l}\text { Use Real-Time analysis of } \\
\text { data }\end{array}$ \\
\hline
\end{tabular}

Fig 2. Differences b/w supervised and unsupervised learning

\section{CONCLUSION}

From all about point it can be concluded that various sort of examples can be used in our day to day life by implicating learning's of machine learning. The technique of machine learning will help the futuristic efficiency in industries and organization. It will bring a lot of advancement in terms of skills and vision

\section{REFERENCES}

[1]. Inza, I., Calvo, B., Armañanzas, R., Bengoetxea, E., Larrañaga, P., \& Lozano, J. Machine learning: an indispensable tool in bioinformatics. In Bioinformatics methods in clinical research (pp. 25-48), Humana Press, 2010.

[2]. K.P. Murphy, Machine Learning: A Probabilistic Perspective, MIT Press, 2012.

[3]. Khattree, R., \& Naik, D, Machine Learning Techniques for Bioinformatics In Computational Methods in Biomedical
Research (pp. 57-88). Chapman and Hall/CRC, 2007.

[4]. E. Alpaydin, Introduction to Machine Learning, MIT Press, 2014.

[5]. C.M. Bishop, Pattern Recognition and Machine Learning, Springer, 2006.

[6]. An introduction to machine learning theory and its applications,A visual tutorial by Nick Mccrea

\section{Cite this article as :}

Rajesh Yadav, "A Simplistic Overview of Machine Learning", International Journal of Scientific Research in Science, Engineering and Technology (IJSRSET), Online ISSN : 2394-4099, Print ISSN : 2395-1990, Volume 8 Issue 5, pp. 184-187, September-October 2021. Available at

doi: https://doi.org/10.32628/IJSRSET218475

Journal URL : https://ijsrset.com/IJSRSET218475 